\begin{abstract}
Iranica
Abstracta Iranica Revue bibliographique pour le domaine irano-aryen

Volume 34-35-36 | 2017

Comptes rendus des publications de 2011-2013
\end{abstract}

\title{
Lori Khatchadourian. The Achaemenid Provinces in Archaeological Perspective
}

\section{Astrid Nunn}

\section{(2) OpenEdition}

1 Journals

\section{Édition électronique}

URL : http://journals.openedition.org/abstractairanica/41572

DOI : 10.4000/abstractairanica.41572

ISSN : 1961-960X

Éditeur :

CNRS (UMR 7528 Mondes iraniens et indiens), Éditions de l'IFRI

\section{Référence électronique}

Astrid Nunn, «Lori Khatchadourian. The Achaemenid Provinces in Archaeological Perspective », Abstracta Iranica [En ligne], Volume 34-35-36 | 2017, document 35, mis en ligne le 15 juillet 2016, consulté le 26 septembre 2020. URL : http://journals.openedition.org/abstractairanica/41572 ; DOI : https://doi.org/ 10.4000/abstractairanica.41572

Ce document a été généré automatiquement le 26 septembre 2020.

Tous droits réservés 


\title{
Lori Khatchadourian. The Achaemenid Provinces in Archaeological Perspective
}

\author{
Astrid Nunn
}

\section{RÉFÉRENCE}

Lori Khatchadourian. "The Achaemenid Provinces in Archaeological Perspective », in : D. T. Potts, ed., A Companion to the Archaeology of the Ancient Near East. Vol. I-II, 2012, p. 963-983. (Blackwell Companions to the Ancient World)

1 Cet article suit celui de W. Henkelman et frappe par sa moindre cohérence. Que l'A. s'attache au problème de la continuité, des différentes formes d'architecture, de l'habitat privé, des pratiques funéraires ou de l'architecture religieuse le lecteur en ressort plus brouillé qu'éclairé. Trop d'aspects sont traités pour une aire géographique extrêmement grande. Le thème a sans doute été posé de manière trop globale. De plus toute la littérature germanophone semble manquer.

\section{AUTEURS}

\section{ASTRID NUNN}

Université de Munich 